\title{
Revus
}

Journal for Constitutional Theory and Philosophy of

Law / Revija za ustavno teorijo in filozofijo prava

$31 \mid 2017$

Dogmatics and Constitutional Interpretation

\section{La ley penal y la autoridad de la dogmática}

María Laura Manrique, Pablo E. Navarro y José M. Peralta

URL: http://journals.openedition.org/revus/3760

DOI: $10.4000 /$ revus.3760

ISSN: 1855-7112

Editor

Klub Revus

Edición impresa

Fecha de publicación: 10 junio 2017

ISSN: 1581-7652

Referencia electrónica

María Laura Manrique, Pablo E. Navarro and José M. Peralta, « La ley penal y la autoridad de la dogmática », Revus [Online], 31 | 2017, Online since 26 February 2019, connection on 25 May 2019. URL : http://journals.openedition.org/revus/3760 ; DOI : 10.4000/revus.3760

Este documento fue generado automáticamente el 25 mayo 2019.

All rights reserved 


\title{
La ley penal y la autoridad de la dogmática
}

\author{
María Laura Manrique, Pablo E. Navarro y José M. Peralta
}

\section{Introducción}

A principios del siglo XIX, la elaboración de los primeros grandes códigos inició un proceso de transformación jurídica y social de gran trascendencia. A partir del fenómeno de la codificación, la legislación deja de ser un reflejo de usos o costumbres comunitarias y se afianza como un instrumento específico de control social. Este fenómeno se enlaza decisivamente con dos factores de inmensa trascendencia institucional y teórica: (i) la conformación de los elementos básicos del Estado de Derecho, (ii) el surgimiento de la dogmática jurídica, como disciplina especialmente dedicada a la identificación, interpretación y sistematización del derecho positivo. ${ }^{1}$ Aunque el desarrollo de la legislación contribuyó notablemente a la formación del moderno Estado de Derecho. En especial, en este diseño institucional, el legislador asume las cargas de suministrar, de manera clara y precisa, las normas básicas de la comunidad y, como consecuencia de ello, las circunstancias en que el Estado puede aplicar sanciones. A su vez, la dogmática jurídica (y en especial, la dogmática penal) ha cumplido un papel mucho más complejo. Por una parte, la dogmática ha insistido en su papel racionalizador de las decisiones legislativas; en su capacidad de ofrecer, a partir de la sistematización del derecho, una mayor previsibilidad para las decisiones judiciales. De este modo, la dogmática sirve para consolidar el ideal de certeza que caracteriza al Estado de Derecho. Sin embargo, por otra parte, la dogmática se reivindica como intermediario necesario entre las decisiones del legislador y las justificaciones de la decisión judicial. Como consecuencia, la función práctica central de la legislación (i.e., imponer un resultado) resulta afectada.

El objetivo central de este trabajo es, precisamente, mostrar las tensiones que subyacen al progreso de la legislación (como técnica de control social) y el desarrollo de la dogmática. En el caso del derecho penal - que es el área dogmática que analizaremos en este trabajoel desafío a la ley genera un importante problema ya que, a diferencia de otros sectores 
del ordenamiento, es usual admitir que sólo una infracción a la ley penal constituye una justificación para imponer una pena a un determinado individuo. ${ }^{2}$ La ley penal es tanto la base fundamental para la construcción de un Estado de Derecho como un requisito para implementar los ideales que expresa ese diseño institucional. ${ }^{3}$ Así, en la medida en que la dogmática representase un desafío al valor de la ley también generaría un mayor riesgo de fracaso en la consolidación de los ideales morales que representa el Estado de Derecho. Por supuesto, nada de esto pretende negar otras importantes funciones que pueda cumplir la dogmática, sino que el propósito es señalar el precio que debemos pagar para conseguir esas otras ventajas.

Finalmente, es preciso señalar algunos presupuestos y límites de nuestro análisis:

(1) En primer lugar, nuestra tesis (i.e, la existencia de una tensión entre dogmática y legislación y la progresiva disminución del valor de la ley como consecuencia de las reformulaciones dogmáticas) no pretende destacar una novedad ya que la crítica al papel desempeñado por la ciencia jurídica, y la dogmática penal en particular, han sido tan persistentes como las voces que se alzan en su defensa. Más bien, nuestro interés radica en suministrar un argumento (relativamente) novedoso para defender esas tesis críticas tradicionales. Como señala Waldron, articular un modelo de legislación que la presente como un modo digno de gobierno y una respetable fuente de derecho es parte de una teoría analítica del derecho, ${ }^{4}$ y por ello, nuestros argumentos principales se basan en herramientas conceptuales específicas, desarrolladas en las últimas décadas por la teoría del derecho. Específicamente se señala que la naturaleza de las reglas y el lenguaje impide alcanzar determinados ideales que pretende implementar el Estado de Derecho y que la dogmática penal diagnostica con precisión esa situación, pero que ella carece de aptitud para formular una respuesta mejor.

(2) En segundo lugar, en este trabajo dejaremos de lado la inmensa discusión acerca del modo en que la relevancia de fuentes positivas supranacionales, la justicia transicional, el derecho internacional humanitario y el llamado derecho penal internacional han transformado el alcance y fuerza del principio de legalidad. A la luz de esas modificaciones, el contenido clásico del principio de legalidad (i.e., la ley como exclusivo fundamento del castigo penal, la inviolabilidad de la jurisdicción natural, la prescripción de las acciones penales, etc.) es refinado una y otra vez, con el propósito de evitar la impunidad penal..$^{5}$ Con independencia de si ello constituye o no una manera adecuada de abordar esos problemas, no analizaremos aquí hasta qué punto ello implica un desafío a la relevancia de la legislación.

(3) En tercer lugar, y estrechamente ligado al presupuesto previo, también dejaremos de lado el enorme debate en torno a la relevancia de los principios morales y su incorporación al derecho constitucional y ordinario, ${ }^{6}$ y su impacto en las teorías neoconstitucionalismo. ${ }^{7}$ La razón para ello es que aún no está claro el papel que ha desempeñado este 'movimiento teórico' en la consolidación del Estado de Derecho. Por ejemplo, en un libro reciente, Fernando Atria (2016: 27-28) señala:

El neo-constitucionalismo constituye /.../ una involución a formas jurídicas premodernas que, en las circunstancias actuales, implica la disolución del derecho. Para resistirlo se necesita una teoría que /.../ entienda a la ley como la forma más plena de manifestación del derecho[.]

En otras palabras, incluso cuando se admite el papel que los principios juegan en el derecho, bien podría ocurrir que, por una misma cuestión de principios, el derecho penal 
tuviese que estar configurado exclusivamente sobre leyes claras y precisas, para evitar el modo en que se regulaban las conductas en el derecho penal pre-moderno. ${ }^{8}$

\section{Crisis de la ley y autoridad del legislador}

Como señala MacCormick (1978: 57 y ss), en el Estado moderno la legislación es par excellence el proceso mediante el cual se producen las normas válidas, es decir, aquellas que los ciudadanos deben obedecer y que los jueces deben usar para justificar sus decisiones. Para que la legislación pueda cumplir con su función de establecer el marco normativo básico (i.e., 'las reglas de juego' de una determinada comunidad) es fundamental que esas reglas tengan autoridad y es usual asumir que esa autoridad deriva de la autoridad política del legislador. A su vez, la autoridad del legislador se manifiesta en su aptitud para cambiar voluntariamente la calificación deóntica de las acciones. Precisamente, a diferencia de la moral, uno de los rasgos característicos del derecho es que sus normas pueden ser modificadas de manera deliberada por las autoridades; que el legislador, al decir que algo es obligatorio o permitido, modifica el estatus normativo de las conductas. ${ }^{9}$

Sin embargo, es un hecho bien conocido que la autoridad del legislador es frecuentemente puesta en entredicho. Uno de los desafíos esta autoridad surge de la tarea de la dogmática jurídica. Por ejemplo, casi un año después de la publicación de uno de los primeros grandes códigos, el Código Civil Francés, en 1805, Jacques de Maleville publicó uno de los primeros comentarios a este texto normativo. Es usual añadir que Napoleón, al tomar conocimiento de ese hecho, exclamó que su Código estaba perdido. Esta anécdota ilustra la idea general que guía este trabajo: la tensión que existe entre la autoridad del legislador y la autoridad de la ciencia jurídica; entre la voluntad política y el conocimiento científico, entre legislación y dogmática.

Es una obviedad señalar que a lo largo de dos siglos la dogmática ha consolidado su prestigio e influido decisivamente en la evolución de la jurisprudencia. A su vez, el papel del legislador, su aptitud para regular la vida social mediante normas expresamente formuladas, ha sufrido sucesivas crisis que erosionan su autoridad. En ocasiones, la desconfianza a la legislación surgió de la desilusión. La confianza ingenua y desmedida en las capacidades de la legislación para obtener soluciones a los problemas sociales mediante la formulación de normas generales y abstractas llevo a una suerte de inflación legislativa, que en muchas ocasiones produjo resultados opuestos a los que se intentaban lograr. Como señala Eugenio Bulygin (1991: 411):

No es en modo alguno obvio que la solución anticipada de problemas por medio de normas generales sea preferible o sea siempre preferible a la decisión particular, aun cuando ésta no esté basada en una norma general prexistente, sino en consideraciones de equidad y justicia. Lo que hay en el fondo de este dilema es una confrontación entre los valores de seguridad jurídica por un lado y de justicia por el otro. Lo que importa es darse cuenta de que se trata de un importante problema valorativo y no proceder ciegamente como si no existiera ningún problema.

Con frecuencia, el desprestigio de la legislación (y de las autoridades encargadas de formularla) surgió del descuido o el oportunismo con que se abordaron legislativamente problemas sociales relevantes. El resultado de estas censurables actitudes políticas se plasma, muchas veces, en una legislación confusa en su formulación, incoherente en sus propósitos, ineficiente en la práctica. En verdad, existen sectores legislativos 
impenetrables no sólo para los ciudadanos sino también para los jueces y especialistas. Por ejemplo, Luigi Ferrajoli afirma (1995: 10):

En efecto, la inflación legislativa, en gran parte coincidente con la inflación penal, se encuentra en el origen de una creciente falta de certeza, oscuridad y dificultad de conocimiento del derecho que favorece una adicción al ilegalismo difuso y a veces inevitable en ese contexto, resta credibilidad y eficacia a la acción penal y ofrece, en consecuencia, el mejor caldo de cultivo a la corrupción y al arbitrio.

Pero, al margen de la ingenuidad del legislador o del descuido y arbitrariedad de muchos de sus proyectos legislativos, el valor de la ley como instrumento racional de control social también se ve amenazado por la permanente revisión y reformulación de las leyes que emprende la dogmática. Para comprender los alcances de este desafío que la dogmática representa para la autoridad del legislador es conveniente destacar tres ideas intrínsecamente relacionadas. En primer lugar, la explicación de la naturaleza de la autoridad está intrínsecamente conectada a la explicación de la naturaleza del derecho y ello significa, en última instancia, dar cuenta del tipo de razones para la acción que la autoridad genera mediante sus decisiones. ${ }^{10} \mathrm{En}$ segundo lugar, la autoridad del legislador representa un valor instrumental en el sentido de que las decisiones de una autoridad legítima reflejan el balance de razones moralmente adecuadas. La función de estas autoridades es identificar las mejores soluciones disponibles para un determinado problema práctico y, mediante sus normas generales y abstractas, disponer qué razones son las que jueces e individuos deben seguir para comportarse correctamente. La autoridad legítima presta un servicio a los miembros de la comunidad, cumpliendo un papel de intermediario entre las razones morales ordinarias (que ella evalúa y pondera) y las decisiones de jueces e individuos. Finalmente, el legislador ejerce autoridad cuando cumple efectivamente ese servicio. Las decisiones del legislador tienen autoridad (o mejor, reconocemos autoridad a sus normas) cuando ellas excluyen la formación de un balance de razones que indique qué se debe hacer. Para que sea posible desempeñar esa función, las decisiones deben expresar de manera precisa qué comportamientos son obligatorios, prohibidos y permitidos. En la medida en que esas normas sean vagas (o contengan conceptos morales abiertos al debate sobre su aplicación, o la formulación sea ambigua, etc.), los destinatarios de esas normas no tendrán más opción que reabrir el balance de razones y con ello, la legislación dejará de prestar el servicio que legitima su autoridad.

El desafío que lanza la dogmática al papel del legislador comienza, a menudo, con la reivindicación del papel del intérprete como un complemento indispensable a la tarea del autor. Más allá de la mayor o menor pericia del legislador, la dogmática insiste en la inevitabilidad de la interpretación de las leyes. En este sentido, Bacigalupo (1999: 21) señala que con independencia de la claridad de un texto normativo, 'el dogmático penal se encuentra ante la necesidad de decidir a favor de una u otra interpretación del derecho positivo penal, sin que pueda deducir su decisión de los textos legales'. Ello significa que existiría una brecha inevitable entre la ley y su aplicación; entre el alcance de las normas y los casos que ellas regulan. Por tanto, los mecanismos para superar racionalmente esa brecha ya no pueden encontrarse en la ley misma y los jueces tienen que recurrir a un discurso alternativo (i.e. la dogmática) para superar esas indeterminaciones. La insistencia de la dogmática en su papel esencial de traducción del lenguaje del legislador, su crítica permanente a los sistemas normativos vigentes, su vocación de contribuir a la justificación de las decisiones judiciales, su preocupación por derivar normas y soluciones de categorías independientes a las normas formuladas por el legislador conlleva un 
inevitable escepticismo acerca del papel que pueden cumplir las leyes - incluso las buenas leyes. En pocas palabras: la justificación que la dogmática elabora de su tarea implica, en mayor o menor medida, una desvalorización de la ley.

\section{Modelos de dogmática}

En un sentido amplio, la dogmática abarca diferentes actividades. ${ }^{11}$ Podría decirse que estas tareas constituyen, en rigor, 'dogmáticas' independientes. Sin embargo, lo usual es entender que todas ellas son parte de una misma disciplina. Roxin (1997: $\$ 7 \mathrm{~nm} .1$ ), quien es probablemente su mejor exponente contemporáneo, resume esos quehaceres del siguiente modo: ${ }^{12}$

La dogmática penal es la disciplina que se ocupa de la interpretación, sistematización y elaboración y desarrollo de las disposiciones legales y las opiniones de la doctrina científica en el campo del Derecho penal.

En un sentido un tanto diferente, la dogmática hace referencia solo a la teoría del delito ${ }^{13}$. Esta se ocupa únicamente de 'los presupuestos generales de la acción punible' y, en este caso, las categorías centrales de análisis son la acción, la tipicidad, la antijuridicidad y la culpabilidad..$^{14}$ Han sido principalmente los doctrinarios de tradición alemana quienes han destacado en este último campo de trabajo intelectual y es allí donde la academia penal tiene su más elevado prestigio. Una de las principales herramientas de este trabajo dogmático es la idea de 'sistema', entendido como el 'orden lógico de los elementos del delito y, con ello, [de] los presupuestos de la punibilidad legalmente regulados'. ${ }^{15}$

Ya sea en sentido amplio, que pretende abarcar cualquier actividad interpretativa o de sistematización, o en sentido más bien restringido, que abarca solo la teoría del delito, la dogmática tiene pretensiones de utilidad para los jueces. En general, esta pretensión se asienta sobre la idea de que el mensaje del legislador tiene que ser inevitablemente completado por la interpretación dogmática, que de esa manera reclama un papel imprescindible de intermediario entre la ley y la decisión judicial. Las observaciones que siguen de aquí en adelante se refieren sobre todo a la dogmática del hecho punible, pues allí es donde se pueden ver con más nitidez tanto las pretensiones de la dogmática en este sentido, como sus debilidades para hacerlo. ${ }^{16}$

Dejando de lado muchas sutilezas y complejidades históricas en el desarrollo de la dogmática penal, es interesante contrastar dos grandes concepciones, que podemos denominar concepción clásica y concepción contemporánea respectivamente. Ambas concepciones pretenden un status científico específico para sus desarrollos conceptuales, pero sus objetivos y metodología difieren significativamente.

Para la concepción clásica, la tarea de la dogmática consiste en dar cuenta de cómo es el derecho de una comunidad y ello requiere la interpretación y exposición sistemática de las normas que ha formulado el legislador penal. A su vez, esta tarea es conceptualmente diferente del análisis de cómo debe ser un determinado sistema penal ideal. Por el contrario, la concepción contemporánea asume que las decisiones del legislador no agotan el contenido relevante de lo que dispone el derecho penal y que la dogmática cumple una indispensable función normativa identificando normas y soluciones que se pueden invocar - con independencia de que ellas hayan sido recogidas por el legislador penal - para justificar decisiones.

Para la concepción clásica, la base del conocimiento científico del derecho penal es la existencia de normas penales - y sus correlativos deberes y obligaciones - que pueden ser 
identificadas de manera objetiva y neutral. De otro modo, el fundamento de los enunciados dogmáticos sería sólo una expresión de puntos de vista, de actitudes subjetivas y preferencias personales de cada uno de los juristas. La relevancia del aporte de la dogmática estaría garantizada por su autoridad teórica, por su búsqueda de la verdad basada en su capacidad científica. Siguiendo este rumbo metodológico, la dogmática clásica acepta que la verdad de sus afirmaciones constituye un criterio decisivo para evaluar la corrección o incorrección de una determinada reconstrucción teórica. Pero, este compromiso conceptual enfrenta un desafío inmediato: ¿qué hechos determinan la verdad de una afirmación acerca de lo que el derecho dispone? Una respuesta simple sería que el valor de verdad de los enunciados jurídicos depende exclusivamente de la existencia de normas formuladas por el legislador. Por consiguiente, en este enfoque clásico, las afirmaciones referidas a los deberes penales son verdaderas o falsas conforme a si el legislador ha formulado expresa o implícitamente una norma en el sistema penal de una cierta comunidad que impone ese deber.

A pesar de que hemos denominado dogmática clásica a esta perspectiva, sería un error creer que ella ya no cumple función alguna en la actualidad o que no tiene cabida en el futuro de la dogmática penal. Como señala Roxin (2008: 362):

La ciencia del Derecho penal también tendrá en el futuro como tarea fundamental

la sistematización, interpretación y desarrollo del Derecho nacional vigente, esto

es, la dogmática jurídico-penal en sentido clásico.

Por supuesto, los dogmáticos clásicos no siempre concuerdan con las normas que formula la autoridad y, con frecuencia, sugieren modificaciones y reformas, pero estas tareas críticas no se consideran parte de la dimensión científica de la disciplina. Más bien, se asume que este aspecto crítico de la dogmática es conceptualmente secundaria respecto a la identificación y sistematización del orden positivo ya que sólo una vez que se han derivado las soluciones que el derecho ofrece a un cierto problema es posible determinar si ellas son correctas o si, por el contrario, requieren modificaciones.

Como respuesta a este modo de entender este enfoque de la dogmática penal se desarrollaron otras perspectivas que ponen el acento en los aspectos normativos y críticos de la tarea dogmática. Más allá de las importantes diferencias específicas entre estos enfoques alternativos, hay una característica sobresaliente que, de cierta manera, confiere un aire de familia a todas estas propuestas y da forma a lo que, por razones de simplicidad, denominaremos la concepción contemporánea de la dogmática penal. Este aire de familia está dado por la convicción acerca de la naturaleza normativa de las propuestas dogmáticas y su función de control racional de las decisiones judiciales. En otras palabras, por la aceptación explícita de que la labor crítica y normativa es una parte legítimamente genuina del trabajo dogmático.

Este rasgo de la concepción contemporánea puede ser brevemente caracterizado de la siguiente manera. Las teorías dogmáticas rara vez se limitan a una exposición neutral de lo que prescribe el legislador sino que imponen criterios de interpretación, construyen jerarquías normativas y delimitan conceptos. La dogmática tiene, por así decirlo, una 'vocación práctica', que se manifiesta en una exigencia de aportar soluciones justas y socialmente adecuadas a los problemas normativos. Como señala Roxin (1992: 63), 'la dogmática penal no es un juego mental ajeno a la vida, sino una ciencia orientada a la praxis, para el estado libre y seguro de la sociedad'.

Esta perspectiva dogmática propone criterios de corrección tanto de las normas del legislador penal como también de las decisiones judiciales. Estos criterios pretenden 
justificar las respuestas a los diversos problemas normativos y ofrecer un fundamento racional a la solución de los conflictos sociales. Por ello, con frecuencia se afirma que el desarrollo de la dogmática es imprescindible para reducir la arbitrariedad y garantizar imparcialidad en la interpretación y aplicación del derecho ${ }^{17}$. Una consecuencia natural de este enfoque sobre la naturaleza y función de la dogmática es la convicción en que un mayor desarrollo dogmático tiene efectos prácticos beneficiosos, que contribuye a la solución racional de nuestros problemas normativos. Ésta sería, en palabras de Silva Sánchez (1992: 44), la 'verdadera misión' de la dogmática:

Con ello podemos afirmar que disponemos de una caracterización de la dogmática que nos aproxima a su verdadera misión: añadir a los enunciados de la ley otros enunciados, que se emplean en la fundamentación de las decisiones junto a la ley misma.

Las normas dogmáticas - que son normas complementarias o alternativas a las que propone el legislador - determinan con precisión las situaciones fácticas relevantes y sus consecuencias normativas, y, por ello, limitan la discreción de los órganos de aplicación del derecho. La consecuencia que emerge es que la ley (en particular, la ley penal) pierde su carácter exclusivo de justificación de las decisiones judiciales ya que junto a ella surgen las normas dogmáticas ofreciendo fundamentos novedosos (i.e., distintos a los originariamente establecidos en la ley) a las decisiones judiciales.

Si se admite esta caracterización, entonces también hay que aceptar que la 'vocación práctica' de la dogmática está ligada, a la justificación de las decisiones judiciales. Por supuesto, hay diferentes sentidos en los que se puede decir que la dogmática penal pretende colaborar con una 'mejor justificación' (o 'buenos resultados') de las decisiones judiciales. A efectos de evitar equívocos, es conveniente distinguir entre las siguientes cuestiones:

(1) En primer lugar, 'buenos resultados' puede significar que el desarrollo de la dogmática torna previsible a las soluciones judiciales. Quizás quien mejor haya resumido esta pretensión es Gimbernat Ordeig. Este autor (Gimbernat Ordeig 1990: 158) afirma que la dogmática penal: ${ }^{18}$

Hace posible /.../ al señalar límites y definir conceptos, una aplicación segura y calculable del Derecho penal, hace posible sustraerle a la irracionalidad, a la arbitrariedad y a la improvisación. Cuanto menos desarrollada esté una dogmática, más imprevisible será la decisión de los tribunales, más dependerán del azar y de factores incontrolables la condena o la absolución.

Esta creencia, ampliamente sostenida en la dogmática, ${ }^{19}$ supone una tesis normativa y una tesis empírica. La tesis normativa dice que es bueno que las soluciones de las autoridades judiciales sean previsibles. La razón por la cual la idea de previsibilidad juega un rol importante en el derecho es bastante obvia. Esto les permite a los individuos predecir las consecuencias de sus acciones, y organizarse en consecuencia, al saber qué pueden esperar de los jueces. La dogmática aportaría así un perfeccionamiento del principio de legalidad, si es que se entiende que la búsqueda de previsibilidad es una de las funciones de este principio.

La tesis empírica, por su parte, asume que la dogmática efectivamente trae consigo soluciones judiciales más previsibles. Esto puede ser pensado desde un análisis cuasi global, según el cual pueda afirmarse que es verdad que en los países donde se usa la dogmática las decisiones judiciales son más predecibles; ${ }^{20} \mathrm{o}$ más bien regional, afirmando, por ejemplo, que las decisiones de las autoridades argentinas son más previsibles, porque aquí se usa el método dogmático o incluso que los jueces que se valen de la dogmática son 
jueces más predecibles. También cabe una afirmación hipotética en los casos en que esto, a nivel global o regional, no ocurra. Según ella, las decisiones judiciales serían más previsibles si se apelara al método dogmático, pero esta presupuesto rara vez es puesto a prueba mediante su corroboración empírica.

(2) En segundo lugar, la contribución dogmática a la justificación de las decisiones judiciales puede entenderse desde una perspectiva valorativa, especialmente, a partir de la explicitación de la orientación teleológica de la dogmática. En este sentido, la dogmática sería una continuación de la 'política criminal'. ${ }^{21}$ Por 'política criminal' pueden entenderse diferentes cosas en este ámbito. Algunos autores parecen identificar 'política criminal' con justificaciones consecuencialistas del castigo, ${ }^{22}$ pero, en rigor, no hay nada en esa expresión que impida incluir también argumentaciones deontológicas, especialmente las relativas a los límites al uso del poder penal. Hacia la primera clase de razones se orienta la siguiente afirmación de Schünemann (2008: 10):

puesto que el fin primario del Derecho penal consiste en la protección de bienes jurídicos a través de la prevención general amenazadora, los presupuestos de punibilidad que conforman el sistema penal pueden ser derivados por medio de una reducción de medios a fines.

En este sentido, la dogmática, y en concreto, la teoría del delito, sería una construcción concebida según su utilidad para (contribuir a) evitar la comisión de delitos. A su vez, con una orientación deontológica se utiliza, por el contrario, el principio de culpabilidad, según el cual la responsabilidad moral debe ser condición de la responsabilidad penal. ${ }^{23}$

Pero, en todo caso, de lo que se trata es de lograr una solución correcta, con apoyo en ciertas premisas de política criminal. La dogmática habría ayudado a asegurar mejores resultados, en este sentido, al destacar, por ejemplo, la diferencia valorativa entre causas de justificación y causas de exculpación. ${ }^{24}$

(3) Finalmente, la dogmática contribuye a la justificación de decisiones al reconstruir el material jurídico como un sistema. En palabras de Roxin (1997: $\$ 7 \mathrm{~nm}$. 2), la existencia de un sistema, de 'un todo ordenado conforme a principios', hace visible, 'simultáneamente, la conexión interna de los dogmas concretos'. Dos soluciones jurídicas son coherentes en la medida en que ambas resuelvan del mismo modo el mismo caso genérico (coherencia jurídica) o si resuelven dos casos genéricos distintos que tienen el mismo fundamento normativo en el mismo sentido (coherencia político criminal). Se trata, en todo caso, de posibilitar la determinación de si cierta construcción teórica (por ejemplo, la del finalismo) padece contradicciones. El método dogmático, y especialmente su aspiración sistemática, permitiría evaluar esto con rapidez. ${ }^{25}$

La idea de sistema también permitiría ver rápidamente cómo la alteración de alguna de sus piezas puede afectar la estructura general. Por ejemplo, si se admitiera que la tentativa debe tener menos pena que el delito consumado, solo en el supuesto de tentativa inacabada, entonces la participación en un hecho tentado debe tener menos pena que la participación en un hecho consumado, solo en la tentativa inacabada. Un cambio para el autor, implica un cambio para el partícipe en la medida en que la razón que lo fundamenta se aplique a ambos.

Estos son las principales estrategias de justificación de la tarea dogmática contemporánea. Frente a la inevitable indeterminación e imperfección de la ley penal, la dogmática asume un papel protagonista, como un intérprete necesario para que los jueces ofrezcan 'buenas soluciones' y el derecho penal sea un instrumento racional de control social. Por supuesto, son numerosas las críticas que se han formulado al desarrollo de la 
dogmática y su visión optimista acerca del papel que puede cumplir en el control racional de las decisiones penalmente relevantes. ${ }^{26} \mathrm{En}$ ocasiones, las visiones escépticas de la dogmática apuntan a su aridez conceptual, a su escasa capacidad para trascender sus propios argumentos e incidir en los fenómenos sociales o, también, a su falta de legitimidad para añadir nuevas soluciones que complementan o sustituyen a las normas del legislador.

A diferencia de esos enfoques escépticos acerca de la dogmática, nosotros exploraremos un argumento diferente: pretendemos revisar el modo en que el desarrollo dogmático compite con la realización efectiva de los valores subyacentes al Estado de Derecho.

\section{Legalidad y lenguaje ordinario}

En un Estado de Derecho, las autoridades tienen que comunicar claramente a los individuos qué conductas serán correlacionadas con una sanción penal. ${ }^{27}$ Para que sea posible esa comunicación, las autoridades y los destinatarios tienen que compartir un determinado lenguaje, ya que de otro modo no sería posible obedecer esas directivas. La formulación de normas generales sería inútil si el legislador utilizase un lenguaje privado o desconocido para los miembros de su comunidad. Para que los destinatarios puedan motivarse mediante las normas jurídicas, las autoridades tienen que redactarlas en un lenguaje compartido por los miembros de la comunidad, i.e., el lenguaje ordinario. Sólo cuando los individuos comprenden lo que exige el derecho es posible para ellos actuar conforme a la ley o ser responsables por su desobediencia. Esta idea es la que modela a las diferentes versiones del principio de culpabilidad penal. Así según Jakobs (1996: 19):

sólo puede cumplir una determinada orden quien tiene la voluntad de acatar tales órdenes, es capaz de reconocer que esa orden se dirige a él y además puede conocer qué es lo que hay que hacer para cumplir la orden.

Por esa razón, el lenguaje ordinario es la base común y natural para la formulación de las normas penales $-\mathrm{y}$, también, de otras normas del ordenamiento jurídico. Las palabras de los lenguajes naturales reciben su significado de convenciones sociales, que poseen siempre una limitada especificidad. Ello implica que es inevitable un cierto margen de indeterminación y que, en algunos casos, no podemos determinar de antemano si la regla o convención que rige el uso del concepto exige o descarta su aplicación. Dadas estas indeterminaciones sintácticas y semánticas (e.g. conceptos vagos, términos ambiguos, conceptos valorativos, etc.) se torna imposible una regulación completa y precisa de todas las circunstancias en las que el Estado puede aplicar una sanción penal.

Estas características de las normas legisladas, i.e. su relativa indeterminación, muestra la limitación no sólo de la precisión de las leyes sino también de las exigencias que impone el Estado de Derecho. En particular, (i) la exigencia de formular las normas en un lenguaje ordinario, compartido entre autoridades y destinatarios, (ii) la exigencia de normas claras y precisas, y (iii) la exigencia de comunicar las normas a los destinatarios son conjuntamente incompatibles. En tanto que el legislador comunique sus normas en un vocabulario común - i.e. el lenguaje ordinario -, ellas tendrán un déficit de precisión y, por el contrario, cuánto más precisas sean las leyes, ellas tendrán que elaborarse en un lenguaje diferente al lenguaje usual compartido y serán más difíciles de comunicar a sus destinatarios.

Esta tensión es de naturaleza conceptual y no depende de la mayor o menor pericia de nuestros legisladores. A la luz de estas relaciones entre derecho y lenguaje, no hay 
escapatoria para este dilema que permita preservar la certeza y claridad de las normas junto a su necesaria comunicación a los destinatarios. Hay diferentes estrategias para mitigar el impacto de ese dilema como, por ejemplo, desarrollar reglas interpretativas que permitan precisar y controlar la aplicación de las normas. Pero, en la medida en que estas reglas interpretativas también se formulan en un determinado lenguaje, ellas no pueden garantizarnos una solución clara para cualquier controversia.

En este punto se advierte el atractivo de la tarea dogmática. Su contribución permite una exposición sistemática de los defectos de la ley así como también una elaboración de diferentes soluciones a esas deficiencias. Por esa razón, la dogmática reclama que su desempeño no es sólo conveniente sino también necesario ya que, en la búsqueda de claridad y certeza para una justificación de las soluciones, la ley y los recursos interpretativos tradicionales serían insuficientes. El modo de superar las deficiencias de la legislación sería mediante el auxilio que proporciona la ciencia jurídico penal a los funcionarios y ciudadanos.

Sin embargo, esa intervención de la dogmática supone un problema para el ideal de Estado de Derecho ya que la reelaboración del material legislativo resulta en la formulación de normas parecidas a las que propone el legislador. Dado que el Estado de Derecho no permite a castigar a sus ciudadanos por la infracción de normas análogas a las que formula el legislador, entonces no es fácil comprender qué otorga legitimidad a la aplicación de sanciones por la infracción a normas que se parecen a las que formula el legislador.

\section{Dogmática, analogía y reglas semánticas}

Una de las maneras en que la dogmática cumple su propósito de intermediario necesario es mediante la formulación de una serie de pautas, normas y definiciones que proporcionan los dogmáticos para que los jueces puedan aplicar de manera racional e imparcial al derecho. Por ejemplo, recordemos que según Silva Sánchez (1992: 49), la verdadera función de la dogmática es 'suministrar al juez criterios para la determinación de qué casos son iguales y cuáles son distintos, y para la adopción del tratamiento adecuado para cada uno de ellos'. En gran medida, esta tarea de establecer semejanzas y analogías es cumplida a través de la enunciación y aplicación de reglas semánticas que reconstruyen los significados de las expresiones del legislador. La tarea del dogmático se dirige a determinar cuándo un cierto evento cuenta (puede ser clasificado) de una cierta manera penalmente relevante, i.e. cuando una cierta X cuenta también como $\mathrm{Z}$.

Para ilustrar esta idea podemos analizar el modo en que opera una definición legislativa, e.g. la definición de 'violencia' del Código Penal argentino, según la cual se comprende también al uso de medios hipnóticos y narcóticos. Esta definición amplia el significado que esa palabra tiene en el lenguaje ordinario $y$, de esa manera, eventos diferentes como, por ejemplo, el uso de la fuerza física y la hipnosis son agrupados en una clase común. Mediante las definiciones legales, el legislador señala que se aparta del uso común de las palabras e indica el sentido que le atribuye a un determinado término. En general, la dogmática también opera de una manera similar. Por ello, para Gimbernat Ordeig (1999: 36-38), gran parte de la tarea del dogmático era ofrecer a los jueces respuestas claras y precisas a preguntas como las siguientes:

¿Qué quiere decir el 'voluntarias' del artículo 1 del Código Penal? ¿Ha de ser

interpretado como dolosas o como voluntad en un sentido neutro, o como 
culpabilidad, o como voluntad referida - opuesta - a la norma? ¿Ha realizado - y por ello debe ser castigado por tentativa de robo - o no - y por ello debe ser absuelto un acto ejecutivo el sujeto que, dirigiéndose a robar es sorprendido en el momento de apoyar la escalera en la tapia para penetrar por la ventana? ¿Cuándo empieza y cuándo termina la noche, esto es: qué oscuridad es precisa para que entre en juego la agravante de nocturnidad? ¿Coopera al delito con un acto sin el cual no se hubiera efectuado el partícipe que proporciona la cicuta al asesino? ¿Qué sucede con el que cree que es preciso romper una puerta para apagar el incendio, resultando después que no había ningún incendio en la habitación, en que entró violentamente, sino que sólo se estaba asando un cordero? ¿Podrá eximirse de los daños apelando al estado de necesidad? ¿Es asesinato por medio de incendio el que mata a otro rociándole de gasolina y prendiéndole fuego? ¿Es hurto o estafa tomar una bolsa de azúcar de un supermercado y pasar por delante del control ocultando la mercancía? ¿En qué se diferencia el hurto de la apropiación indebida? ¿Comete estafa el charlatán que asegura de unas gafas de sol, para incrementar sus ventas, que cuestan en la tienda cien pesetas - lo que es mentira -, pero vendiéndolas a su precio real de diez pesetas? ¿Es una fotografía un documento, siendo falsedad, por ello, la suplantación de una fotografía por otra en un instrumento de identificación? ¿Es robo con fractura romper una puerta, no para entrar en el recinto donde está la cosa, sino para salir de él después de haberse apoderado de ella? ¿Comienza la prescripción en el abandono de familia cuando el padre huye a Sudamérica o no se ha consumado el delito mientras no haya cesado el alejamiento del hogar? Y en las detenciones ilegales: ¿cuándo comienza a contar el plazo: cuando se encierra al sujeto o cuando se le pone en libertad?

Conforme a esta reconstrucción, los desarrollos dogmáticos con frecuencia se traducen en especificaciones interpretativas del lenguaje que el legislador ha escogido en su formulación de la ley penal. Al menos, todas las preguntas que menciona Gimbernat Ordeig parecen reducirse a especificaciones acerca de cuándo 'algo' (e.g. una fotografía) cuenta como otra cosa (e.g. un documento) y el modo tradicional de responder a ese interrogante es definiendo los respectivos conceptos.

Con independencia de las razones y valores que guían a los dogmáticos en su tarea de definir, el resultado de sus actividades es ofrecer una definición, es decir, una regla semántica que indique de manera específica el modo en que hay que entender las palabras de la ley. Estas reglas son las que sirven como criterios de semejanzas y diferencias y dan a los jueces las herramientas que permiten tratar de igual manera a casos semejantes. Por supuesto, es necesario subrayar que las semejanzas son constituidas por esas reglas, al menos en el sentido de que si ellas no existieran como criterio de comparación y clasificación no tendríamos fundamentos para agrupar a eventos que son individualmente diferentes en una misma clase.

En general, las definiciones pueden ser de dos tipos diferentes: lexicográficas y estipulativas. En el caso de las primeras, la definición se limita a mencionar el modo en que se usan las palabras en una comunidad. Una definición lexicográfica es una información acerca de las reglas de uso vigentes en un cierto grupo. Por el contrario, una definición estipulativa es, normalmente, una expansión o contracción del sentido ordinario de un término. Ya no se trata de una información acerca del uso vigente sino en una decisión acerca de cómo debe entenderse una cierta expresión. Por ejemplo, supongamos que intentamos determinar cuándo una determinada acción puede ser considerada como desistimiento en el ámbito de la tentativa. Las diferentes doctrinas acerca de lo que define el desistimiento en la tentativa son relevantes porque no se encuentra una definición de ese concepto en el vocabulario empleado por el legislador y porque ese concepto es notoriamente vago en su uso en el lenguaje ordinario. Un 
desarrollo dogmático del desistimiento en la tentativa que pretenda superar ese problema tendrá, entonces, que plasmar una propuesta que resuelva las indeterminaciones que deja el lenguaje ordinario. En consecuencia, la palabra desistimiento, que en el lenguaje ordinario posee un significado impreciso S1 tendrá en el vocabulario dogmático otros significado S2 de mayor precisión.

La importancia de estos cambios de significado, a menudo, queda oculta por la ambigüedad de la palabra 'norma', que en su sentido ordinario se refiere tanto a los textos aprobado por el legislador como así también a los significados que esos textos tienen. Desde un punto de vista teórico, es conveniente restringir el concepto de norma al significado de los textos normativos ya que la principal función de una norma es motivar conductas. Esa aptitud para motivar depende del significado de una expresión. En la medida en que los ciudadanos no pueden comprender el significado de sus palabras, no pueden motivarse por la representación de la norma y la atribución de responsabilidad infringiría el principio de culpabilidad.

En este sentido, Alchourrón y Bulygin (1991: 442) señalan:

La captación del sentido del enunciado que expresa una norma por parte del destinatario es condición necesaria para que la norma pueda cumplir el papel que le asigna el legislador: el de motivar determinadas conductas sociales. Si el destinatario no captó ese sentido, no puede ser motivado por la norma y no puede obedecerla ni aplicarla; incluso si por algún motivo distinto realiza efectivamente la conducta exigida por la norma, no cabe hablar de obediencia, sino a lo sumo de mera coincidencia entre la conducta prescripta y la que de hecho se lleva a cabo

Si la tarea de la dogmática es refinar el significado de los textos normativos, mediante la elaboración explícita de nuevas reglas semánticas, su tarea resulta en una selección - más o menos arbitraria - de normas posibles de correlacionar con un mismo texto formulado por el legislador. Así, la dogmática especifica condiciones de uso del concepto que no coincide con la propuesta original de la autoridad. Al respecto, Genaro Carrió (1994: 92) señala:

Si la palabra es vaga, cualquier definición que intente recoger con fidelidad sus reglas de uso en vigor, tendrá por fuerza que recoger la imprecisión de la palabra definida. Si por alguna razón particular deseamos dar a la palabra una precisión que ella no tiene... entonces estamos haciendo una cosa distinta de la que hacemos cuando nos limitamos a recoger el significado que la palabra tiene según los usos lingüísticos vigentes. Ahora estamos estipulando un significado, o si cabe la expresión, legislando una nueva regla de uso, de aplicación circunscripta.

Por consiguiente, la intervención de la dogmática, en la medida en que pretende dotar a la ley penal de una precisión que ella no tiene, supone un cambio parcial de la norma expresada por la ley. Por supuesto, este cambio es normalmente llevado a cabo de manera solapada, señalándose sólo que se trata de una nueva interpretación del texto normativo. Como señalan Alchourrón y Bulygin (1991: 444-445),

los jueces muchas veces modifican las normas, sobre todo cuando su aplicación llevaría a resultados manifiestamente injustos o indeseables, por ejemplo, por haber cambiado las circunstancias económicas, políticas o sociales. Pero lo hacen en forma encubierta, tratando de ocultar ese hecho, diciendo que se trata tan sólo de otra interpretación de la misma norma. Así, amparándose en el hecho de que el texto de la ley permanece invariable, pretenden disimular el cambio de la norma. Pero si el sentido del texto depende de la interpretación, otra interpretación significa otro sentido, y si ha cambiado el sentido del texto se ha modificado la norma. 
La nueva norma obtenida con el auxilio de las definiciones dogmáticas puede ser parecida a la norma que anteriormente expresaba la formulación del legislador, pero de todos modos es una norma diferente. Por ello es que la aplicación de esa norma dogmática por parte de los jueces sería una aplicación analógica del derecho penal. La aplicación analógica del derecho es uno de los temas clásicos y recurrentes en la teoría del derecho y no es éste el lugar apropiado para ofrecer un tratamiento sistemático. Sólo señalaremos que si la prohibición de la aplicación analógica es una de las exigencias del principio de legalidad, entonces la dogmática contemporánea - al igual que el legislador - se encuentra frente a compromisos incompatibles: complementar la información normativa suministrada por el legislador y abstenerse de modificar los mandatos legislativos con normas análogas a las que expresa la ley. ${ }^{28}$

En verdad, en los ordenamientos jurídicos contemporáneos parece que la prohibición de la analogía sólo rige para las modificaciones del sentido normativo que no han sido convalidadas por el desarrollo dogmático, pero que una vez que ellas han sido avaladas por la dogmática, entonces dejan de ser expresiones análogas y se convierten en parte del sentido que la ley ya tenía. Al respecto es ilustrativa la siguiente afirmación de Hassemer (1995: 30-31):

La dogmática penal, elaborada conjuntamente con la jurisprudencia y por la ciencia que la sostiene, ha ido cincelando con el correr del tiempo los conceptos 'daño patrimonial' en la estafa, o 'violencia' en el robo, coacción o violación, y en todo caso, los ha trabajado de modo tal que sabe acerca de qué se puede discutir y qué no, hacia donde se dirige el desarrollo en ese momento, y de qué lado están los batallones más fuertes. Esto no es poco. Y sin embargo no alcanza. Quien no está aconsejado o defendido por un jurista penal profesional, en muchas situaciones no puede prever qué es lo que le espera. El Código Penal - justamente por estos cincelamientos y paráfrasis realizados por la dogmática penal - no constituye una fuente confiable, y los comentarios no resultan comprensibles ni accesibles para el lego. Pero tampoco el experto puede, en muchos casos particulares, pronosticar en forma confiable cómo decidirán los tribunales.

Este párrafo revela con claridad la relación que existe entre el desarrollo de la dogmática y el progresivo deterioro del valor de la ley. La afirmación de Hassemer es que 'justamente por esos cincelamientos y paráfrasis realizados por la dogmática penal' el Código Penal deja de proveer información confiable acerca de qué se debe hacer o no hacer. La conjetura que se impone extraer de esa tesis es bastante simple: ¿sería el Código Penal una fuente más confiable para conocer qué se debe hacer en caso de que la dogmática se abstuviese de expandir o contraer el sentido de las palabras de la ley? En esta sección hemos adelantado argumentos a favor de una respuesta afirmativa para este interrogante y es conveniente reiterar la idea principal: si la dogmática se centra en la revisión del sentido de los textos legales, entonces las propuestas dogmáticas siempre van más allá de lo que dice el legislador. De otro modo, la clásica distinción entre lege lata y lege ferenda carecería de sentido. Pero, al ir más allá de lo que dice el legislador, las normas dogmáticas se presentan como alternativas a las soluciones que ofrece la ley. Con independencia de cuán parecidas sean esas propuestas dogmáticas a las normas establecidas por la ley penal, ellas siguen siendo normas análogas a las formuladas por el legislador. Por esa razón, cuando mayor sea el apego a seguir las propuestas interpretativas de la dogmática, menor valor autónomo se le reconocerá a las palabras de la ley. 


\section{Reglas, razones y casos recalcitrantes}

Al igual que ocurre con la legislación, la dogmática necesita ofrecer al juez pautas precisas que sirvan para delimitar las decisiones correctas y, en ese mismo sentido, que identifiquen a las que se considerarán erróneas o arbitrarias. Sólo bajo este supuesto la dogmática contribuye a lograr decisiones racionales (que, en este contexto, significa: más previsibles). La dificultad radica en que la búsqueda de precisión puede limitar la discreción de los órganos de aplicación, pero, a la vez, la precisión introduce distinciones que ensanchan la 'distancia conceptual' entre lo que la ley exige y las razones sustantivas que la justifican..$^{29}$ En el primer caso, la indeterminación que generan las normas imprecisas, y se muestra en la diferente solución que los tribunales ofrecen para casos semejantes. Esta forma de indeterminación puede ser denominada 'discreción'. En el segundo caso, el problema consiste en que al aplicar normas precisas, los funcionarios se apartan de las razones que justifican a esas normas. A efectos de evitar confusiones, se puede denominar a esta situación como 'irrazonabilidad'. Por consiguiente, la búsqueda de precisión parece conducir a un dilema: o bien se incrementa la irrazonabilidad de las normas mediante disposiciones precisas, o bien se incrementa la discreción en la aplicación del derecho mediante normas imprecisas. En cualquiera de los dos sentidos, las propuestas dogmáticas parecen alejarnos de los ideales que definen al Estado de Derecho. 30

Para reducir la arbitrariedad de las decisiones jurídicas es necesario precisar de manera general y abstracta los supuestos de hecho que se conectan con atribución de responsabilidad y para lograr esa precisión es inevitable formular reglas (semánticas o de conducta). Sólo una vez que se asume la fuerza normativa de las reglas, tiene sentido esforzarse en conseguir precisión. ${ }^{31}$ Esta capacidad normativa de las reglas es la que permite que los individuos diseñen y desarrollen sus planes de vida conforme al derecho, ya que no sería demasiado sensato elaborar planes de vida a partir de lo que señalan las reglas si los jueces (y otros funcionarios) tuviesen la libertad de ignorarlas. De igual manera, carecería de sentido que el legislador se esforzase en especificar de manera precisa tanto los delitos como las penas si los órganos de aplicación no estuviesen estrictamente obligados a aplicar las leyes. Si en lugar de reglas sólo se ofreciesen buenos (o malos) consejos acerca de la justificación de las decisiones, entonces todavía no contaríamos con apoyo suficiente para predecir el modo en que se aplicará el derecho. Después de todo, un consejo es sólo una razón más para decidir, pero no representa necesariamente el fundamento de una decisión. Por el contrario, las reglas controlan la decisión en el siguiente sentido: ellas ofrecen una razón para decidir de una manera determinada y excluyen otras justificaciones de la conducta. Las reglas no son una razón más que los jueces tienen que incorporar al balance de razones sino que son una razón para dejar de lado ese balance. La única manera en que las reglas pueden cumplir esa función es señalando pautas de conducta y decisión que pueden ser seguidas sin reabrir el balance de razones y justificaciones.

Una formulación imprecisa no puede funcionar como regla porque su indeterminación exige reabrir el balance de razones para identificar su alcance y relevancia. Sólo formulaciones precisas pueden imponerse como reglas en el contexto de decisión. A su vez, si se admite que la racionalidad (previsibilidad) de las decisiones judiciales depende de la precisión de las normas vigentes en una determinada comunidad, se sigue que tanto 
la legislación como la dogmática tienen que proponer reglas. Pero, cualquier regla - con independencia de si ella es formulada por un teórico o una autoridad - resolverá de manera deficiente diversos conjuntos de casos recalcitrantes. Estos casos recalcitrantes se producen porque la precisión de las reglas exige una especificación de las razones que subyacen y justifican la regla. ${ }^{32} \mathrm{El}$ precio que hay que pagar por la (mayor) precisión es la progresiva distancia respecto de su justificación y la multiplicación de casos recalcitrantes. En esos casos, las reglas y sus justificaciones no coinciden y, a diferencia de lo que ocurre en casos normales, las soluciones racionales se fragmentan. En otras palabras, en casos recalcitrantes las reglas precisas dejan de ser buenas razones para decidir y su aplicación tendrá que ser justificada de manera alternativa.

Esta 'distancia conceptual' entre las reglas y sus justificaciones es inevitable y, por ello, en la medida en que la dogmática pretenda garantizar certeza y racionalidad sus propuestas serán - en mayor o menor grado - defectuosas. En definitiva, no se trata de una dogmática más o menos desarrollada sino de la naturaleza de las reglas. Si la dogmática pretende contribuir a la racionalidad de las decisiones, entonces tiene que formular reglas precisas. A su vez, ellas generan una serie de casos recalcitrantes que exigirán dejar de lado esas mismas reglas y justificar las decisiones de manera alternativa.

El desafío para la dogmática es mostrar que su contribución a la racionalidad de las decisiones judiciales no es sólo un noble sueño. Para ello tiene que mostrar en qué sentido sus propuestas pueden superar a las que elabora el legislador, por qué sus normas pueden tener éxito donde el legislador inevitablemente fracasa. Los argumentos que aquí hemos considerado arrojan dudas sobre la aptitud de la dogmática para superar los límites que surgen de la naturaleza del lenguaje y la naturaleza de las reglas. Más aún, estos límites también nos ayudan a observar a las indeterminaciones de la ley desde otra perspectiva.

\section{Reglas, principios y precisión de las normas}

Según hemos visto, el reclamo de un mayor desarrollo dogmático era una consecuencia de las imperfecciones e indeterminaciones de la ley. La idea no era únicamente que el legislador formulaba normas defectuosas, sino que inevitablemente serían deficientes. Pero, ahora podemos advertir que esas indeterminaciones de la ley, que abren paso a una mayor discreción también pueden servir para prevenir decisiones irrazonables. Así, la precisión impone una inevitable distancia conceptual de las reglas frente a sus razones subyacentes. Ello no significa que tengamos que renunciar a la precisión ya que todavía puede haber otras buenas razones para regular situaciones sociales mediante límites específicos. Estas razones inclinan la balanza frente al precio que representan los casos recalcitrantes. Por ejemplo, aunque parezca irrazonable imponer un límite específico de edad de la víctima, e.g. 12 años para determinar si existe violación, puede ocurrir que, para ese caso, otras consideraciones morales justifiquen esas precisiones. ${ }^{33}$ Ahora bien, ¿podría ocurrir que siempre tengamos mejores razones para ser precisos en lugar de regular la conducta de manera imprecisa?

La respuesta es negativa. Un buen argumento para esta respuesta es el que señala Ferreres (2002:157-158):

Es posible, en efecto, que el juez tenga un cierto margen interpretativo para ponderar una serie de factores relevantes para decidir cada caso. La jurisprudencia puede servir para fijar con mayor claridad cuáles son esos factores, que quizás la ley no explicita. Pero no debe destruir el casuismo que el legislador ha querido 
preservar para cada juez. Así, si un precepto fija una pena de entre tres y cinco años, sería absurdo que el Tribunal Supremos, 'para aumentar la precisión de la ley', estableciera que la pena es exactamente de cuatro años. Habría taxativizado la ley más allá de lo querido por el legislador. De modo análogo, si, por ejemplo, el legislador opta por agravar la estafa cuando, por la cantidad estafada, se ocasiona un 'grave daño patrimonial' para la víctima, sería incorrecto que el Tribunal Supremos estableciera una cantidad determinada (así, 10.000 euros) para concretar el concepto 'grave daño patrimonial'. El legislador ha querido que el juez concrete ese concepto según las circunstancias de cada caso, y no a través de una regla rígida

Aunque en ocasiones tenemos buenas razones para ser precisos, el derecho es inevitablemente impreciso. Nuestro relativo desconocimiento del futuro impide decidir acerca de las diferentes circunstancias que se pueden producir y es conveniente que esos casos imprevistos se resuelvan mediante una nueva decisión. Por ello es que, como sostiene Hart, en cualquier sistema jurídico se combinan reglas que los individuos pueden aplicar por sí mismos con otras pautas normativos, e.g. principios y estándares normativos variables, que requieren de nuevas decisiones oficiales para determinar la correcta solución de los casos individuales. ${ }^{34}$ De esta manera, la oscilación entre precisión y razones es inescapable y siempre habrá situaciones en las que prevalece la necesidad de disminuir la precisión para conseguir una regulación razonable de las relaciones sociales.

La búsqueda de un equilibrio entre la certeza que ofrecen las reglas y la adecuación a razones que proporcionan los principios es una tarea importante y como recuerda Hart (1994: 130),

todos los sistemas, de manera diferente, concilian dos necesidades sociales: por un lado, la necesidad de ciertas reglas que, en relación con grandes áreas de conducta, pueden ser aplicadas con seguridad por los particulares a sí mismos, sin nueva guía oficial o sin necesidad de sopesar cuestiones sociales, y, por otro lado, la necesidad de dejar abiertas para su solución ulterior, mediante una elección oficial informada, cuestiones que sólo pueden ser adecuadamente apreciadas y resueltas cuando se presentan en un caso concreto.

La dogmática, al igual que el legislador, emplea ambas técnicas. En ocasiones formulan nuevas reglas, que se añaden, complementan y eventualmente desplazan a las que formula el legislador y, en ocasiones enuncia principios, que dejan abierto un margen mayor de evaluación de razones en la solución de casos particulares. Pero, indefectiblemente, sus reglas generarán casos recalcitrantes, en los que la solución es arbitraria, y sus principios impondrán soluciones que no podían ser previstas por los individuos. Por ello, cuando Hart (1994: 132) analiza principios como el estándar de 'debido cuidado' en los casos de culpa o negligencia, señala:

Esta técnica deja a los individuos, sujeta a la corrección por un tribunal, la tarea de valorar las pretensiones sociales que surgen de formas diversas no anticipables y de obtener un razonable equilibrio entre ellas. En este caso se les exige que se adecúen a un estándar variable antes de que haya sido definido oficialmente, y puede ser que sólo lleguen a enterarse ex post facto, por conducto de un tribunal, y cuando ya lo han violado, cuál es, en términos de acciones u omisiones específicas, el estándar que ellos deben observar.

La consecuencia de este argumento es que necesitamos proceder con cautela al momento de criticar la imprecisión de las normas y que también es preciso constatar si hay razones que justifiquen el modo en que el legislador ha ponderado la importancia de otros bienes frente a la exigencia de precisión de sus normas. El control dogmático y judicial no tiene que ocuparse de investigar la precisión de las leyes sino de analizar las razones que el legislador invoca para regular las conductas de manera indeterminada. 
Esta nueva perspectiva de la naturaleza de las palabras de ley puede servir para comprender mejor tanto la contribución que la dogmática puede realizar como también el modo en que los tribunales tienen que evaluar a la validez de las leyes imprecisas. En otras palabras, si la imprecisión no es necesariamente un defecto y si los tribunales no censuran al legislador declarando la invalidez de las leyes imprecisas, entonces también hay buenas razones para revisar el fundamento de la crítica de la dogmática a los límites de la ley y la necesidad de aceptar al desarrollo dogmático como un inevitable intermediario entre las palabras de la ley y las justificaciones judiciales.

\section{Conclusiones}

El aporte de la dogmática a la racionalidad de las decisiones judiciales se encuentra ligado a su capacidad de ofrecer razones sustantivas que justifiquen la práctica del castigo. Esas razones sustantivas son, en general, directivas (recomendaciones, reglas, etc.) que formulan los dogmáticos (i.e. normas dogmáticas). La justificación de estas normas dogmáticas radica en su aptitud para capturar las exigencias morales subyacentes a la práctica de atribuir responsabilidad penal. Es decir, las normas dogmáticas son de naturaleza moral y su alcance y fuerza no depende de una formulación canónica específica. Por el contrario, la búsqueda de una mayor especificidad y precisión conspira contra su flexibilidad para adaptarse a diferentes contextos. Por esa razón, la incorporación de normas dogmáticas en el horizonte de justificación de las decisiones compite con otras justificaciones formales, e.g. normas legisladas y, con frecuencia, suponen una tensión entre las palabras de la ley y lo que los dogmáticos dicen que dice el legislador.

La exigencia de legalidad penal, en sus variantes clásicas, era - en primer lugar - una directiva al legislador para que determinase con claridad y precisión las circunstancias en las que el estado está legitimado para el ejercicio del poder punitivo. Esta búsqueda de precisión y claridad está limitada por la naturaleza de la comunicación humana y, entre otras consecuencias, ello significa que las razones morales que justifican las leyes penales nunca son agotadas por las formulaciones del legislador. Si la búsqueda de la dogmática contemporánea se dirige a exponer sistemáticamente esta necesidad de ajuste moral de las leyes del legislador (es decir, una crítica sistemática del derecho positivo), entonces sus propuestas pueden servir para ilustrar los defectos de la legislación, pero no pueden simultáneamente ofrecer precisión y límites específicos que hagan previsible (racional) las decisiones judiciales. En pocas palabras, el fracaso de la ley penal en sus aspiraciones de cumplir con las exigencias del ideal de legalidad también acecha a las normas que formula la dogmática contemporánea.

\section{BIBLIOGRAFÍA}

Carlos ALCHOURRÓN y Eugenio BULYGIN, 1991: Definiciones y normas. Carlos Alchourrón y Eugenio Bulygin, 1991: Análisis lógico y derecho. Madrid: Centro de Estudios Constitucionales. 
Manuel ATIENZA y Juan RUIZ MANERO, 2000: Ilícitos atípicos. Madrid: Trotta.

Fernando ATRIA, 2016: La forma del derecho. Madrid: Marcial Pons.

Enrique BACIGALUPO, 1995: La técnica de resolución de casos penales. 2a ed. Madrid: Colex.

Enrique BACIGALUPO, 1999: Delito y punibilidad. 2a ed. Buenos Aires: Hammurabi.

Gerardo BARBOSA y Carlos BERNAL PULIDO (eds.), 2016: Justicia transicional: retos teóricos. Bogotá: Universidad del Externado.

Hernan BOUVIER, 2010: Consideraciones teóricas y jurídicas acerca del derecho penal internacional. Jura Gentium. Rivista di filosofia del diritto internazionale e della politica global, 2010.

Eugenio BULYGIN, 1991: Teoría y técnica de legislación. Carlos Alchourrón y Eugenio Bulygin, 1991: Análisis lógico y derecho. Madrid: Centro de Estudios Constitucionales.

Eugenio BULYGIN, 2005: El positivismo jurídico. México: Fontamara.

Miguel CARBONELL (ed.), 2003: Neoconstitucionalismo(s). Madrid: Trotta.

Genaro CARRIÓ, 1994: Notas sobre derecho y lenguaje. 4a ed. Buenos Aires: Abeledo Perrot.

Daniela DOMENICONI, 2014: Reflexiones en torno a los fundamentos éticos y políticos de la imprescriptibilidad de los delitos de lesa humanidad. Hernan Bouvier et al., 2014: El juzgamiento de los delitos de lesa humanidad en la Argentina postdictatorial. Cordoba: Ferreyra.

Ronald DWORKIN, 1986: A Matter of Principle. Cambridge: Harvard University Press.

Timothy ENDICOTT, 2000: Vagueness in Law. Oxford: Oxford University Press.

Víctor FERRERES, 2002: El principio de taxatividad en materia penal y el valor normativo de la jurisprudencia. Madrid: Civitas.

Luigi FERRAJOLI, 1995: Derecho y razón. Trad. española de Perfecto Andrés Ibañez, Juan Carlos Bayón et al. Madrid: Trotta.

George FLETCHER, 1985: The Right and the Reasonable. Harvard Law Review (1985) 98. 949-982.

Enrique GIMBERNAT ORDEIG, 1990: Estudios de Derecho penal. 3a ed. Madrid: Tecnos.

Enrique GIMBERNAT ORDEIG, 1999: Concepto y método de la ciencia del derecho penal. Madrid: Tecnos.

Felix HANSCHMANN 2006: Theorie transnationaler Rechtsprozesse. Neue Theorien des Rechts. Eds. Buckel, Christensen y Fischer-Lescano. Stuttgart: Lucius \& Lucius. 347-370.

Herbert L.A. HART, 1994: The Concept of Law. 2a ed. Oxford: Oxford University Press. Winifried HASSEMER, 2003: Crítica al derecho penal de hoy. 2a ed. Trad. española de Patricia S. Ziffer. Buenos Aires: Ad Hoc.

Günther JAKOBS, 1996: Fundamentos del derecho penal. Trad. española de Manuel Cancio Meliá et al. Buenos Aires: Ad Hoc.

Neil MACCORMICK, 1978: Legal Reasoning and Legal Theory. Oxford: Oxford University Press.

Fulgencio MADRID, 1983: La legalidad del delito. Valencia: Universidad de Valencia.

Vittorio MANES, 2012: Il giudice nel labirinto. Roma: Dike.

Juan Pablo MONTIEL, 2009: Analogía favorable al reo. Madrid: La Ley.

Wolfang NAUCKE, 2002: Strafrecht. 10th ed. Neuwied/Kriftel: Luchterhand. 
Pablo NAVARRO, 2005: Los límites del derecho. Bogotá: Temis.

Daniel PASTOR, 2006: El poder penal internacional. Una aproximación jurídica crítica a los fundamentos del Estatuto de Roma. Barcelona: Atelier.

Michael PAWLIK, 2012: Das Unrecht des Bürger. Tübingen: Mohr Siebeck.

Joseph RAZ, 1979: The Authority of Law. Oxford: Oxford University Press.

Joseph RAZ, 1983: The Morality of Freedom. Oxford: Oxford University Press.

Joseph RAZ, 1994: Ethics in the Public Domain. Oxford: Oxford University Press.

Miguel Ángel RODILLA, 2009: Imperio de la ley y principios. Presentación de un debate. Francisco Laporta, Juan Ruiz Manero y Miguel Ángel Rodilla, 2009: Certeza y predecibilidad de las relaciones

jurídicas. Madrid: Fundación coloquio jurídico europeo.

Claus ROXIN, 1992: Política criminal y estructura del delito. Trad. española de Juan Bustos Ramirez y Hernán Hormazabla. Barcelona: PPU.

Claus ROXIN, 1997: Derecho penal, parte general. T. I. 2a ed. Trad. española de Diego Luzón Peña. Madrid: Civitas.

Claus ROXIN, Política criminal y sistema de derecho penal, 2a ed. Trad española de Francisco Muñoz Conde. Buenos Aires: Hammurabi.

Claus ROXIN, 2008: Fundamentos político-criminales del Derecho penal. Trad. española de Carmen Gómez Rivero. Buenos Aires: Hammurabi.

Bernd RÜTHERS, 2007: Rechtstheorie. 3a ed. Múnich: C.H.Beck.

Minor E. SALAS, 2006: La dogmática jurídico-penal: ¿un viaje fantástico al reino de absurdistán o un arma eficaz contra la irracionalidad de la justicia penal? Observar la ley. Ensayos sobre metodología de la investigación jurídica. Ed. Christian Courtis. Madrid: Trotta. 259-276.

Antonin SCALIA, 1989: The Rule of Law as a Law of Rules. The University of Chicago Law Review (1989) 56. 1175-1188.

Frederick SCHAUER, 1991: Playing by the Rules. Oxford: Oxford University Press.

Bernd SCHÜNEMANN, 2008: El sistema propio de la teoría del delito. Indret Penal, 1/2008.

Jesús María SILVA SÁNCHEZ, 1992: Aproximación al derecho penal contemporáneo. 1a ed. Barcelona: Bosch.

Jeremy WALDRON, 1999: The Dignity of Legislation. Cambridge: Cambridge University Press.

Hans WELZEL, 1997: Derecho penal alemán. 11 ed. Trad. española de Bustos Ramirez et al. Santiago de Chile: Editorial Jurídica.

\section{NOTAS}

1. Este proceso es un fenómeno ampliamente conocido. Para una estupenda caracterización de esta relación en el ámbito del derecho penal, véase, Ferrajoli 1995: 209. A ello hay que añadir a la consolidación del positivismo jurídico como teoría jurídica dominante. Al respecto, véase Bulygin 2005: 62 .

2. En adelante, 'regla' y 'norma' serán usadas como expresiones sinónimas para referirse a los elementos del derecho. La palabra 'ley’ se emplea para referirse al resultado de la legislación. 
3. Uno de los aspectos centrales del Estado de Derecho es la adopción del principio de legalidad penal. Este principio comprende varias dimensiones (e.g., reserva de ley, prohibición de aplicación retroactiva de la ley penal, determinación o precisión de la ley penal, etc.) Acerca de esta dimensión del principio de legalidad, véase, Ferreres 2002. En lo sucesivo, nuestro análisis se referirá principalmente a la determinación de la ley penal, dejando de lado a otros aspectos del principio de legalidad.

4. Waldron 1999: 2-3.

5. Entre muchos trabajos críticos acerca de los problemas que estas incorporaciones generan al esquema clásico del derecho penal, véase: Pastor 2006, Hanschmann 2006, Manes 2012, Bouvier 2010, Domeniconi 2014; y los trabajos incluidos en Barbosa, Gerardo and Bernal Pulido 2016.

6. Al respecto, véase, por ejemplo, Dworkin 1986: 9-32, Scalia 1989: 1175-1188.

7. Acerca de la influencia de Dworkin en la conformación de las teorías neoconstitucionalistas, véase, Rodilla 2009: 9-53. También los trabajos recogidos en Carbonell 2003.

8. Al respecto, véase, Atienza y Ruiz Manero 2000: 25-27.

9. Hart 1994: 175-178.

10. Para un desarrollo de estas ideas, véase los diferentes ensayos de Joseph Raz (1979 y 1994). Para una defensa general de la idea de autoridad como servicio, véase, Raz 1983.

11. La literatura acerca de la dogmática jurídica es prácticamente inabarcable. Autores como Carlos Nino, Aaulis Aarnio, Albert Calsamiglia, Giovanni Tarello (entre muchos otros) han aportado importantes análisis a las diversas actividades de la dogmática y su relación con la naturaleza científica de esas tareas. En cierta medida estos trabajos representan una 'mirada externa', propia de la teoría general del derecho. Sin negar la relevancia de esos trabajos, en nuestro artículo basaremos nuestro análisis en ideas extraídas de textos de los dogmáticos penales contemporáneos más importantes. Podría decirse, entonces, que nuestro propósito es comprender a ciertos aspectos de la dogmática penal 'desde dentro', o mediante una 'mirada interna'.

12. También, Rüthers 2007: 321 ff.

13. Por ejemplo, Schünemann 2008: 9.

14. Roxin 1997: §7 nm. 1.

15. Schünemann 2008: 3-5.

16. En este trabajo es inevitable presentar a la dogmática de una manera simplificada y sólo insistiremos en sus rasgos característicos que están vinculados con los principales objetivos de nuestro artículo (e.g., analizar la tensión entre ley penal y normas dogmáticas, o señalar los límites a las propuestas dogmáticas).

17. Por ejemplo, Silva Sánchez 1992: 44. Hay una segunda edición de este libro, publicada en B de F, Buenos Aires/Montevideo, 2010. Se cita conforme a la edición original) Son legión los autores que subrayan esta conexión entre dogmática, certeza y racionalidad, aunque lamentablemente la frecuencia con que ella se invoca en los trabajos de dogmática penal es inversamente proporcional a la evidencia empírica que se ofrece para probar su verdad.

18. Y añade (Gimbernat Ordeig 1990: 158): "Si no se conocen los límites de un tipo penal, si no se ha establecido dogmáticamente su alcance, la punición o impunidad de una conducta no será la actividad ordenada nada y meticulosa que debería ser, sino una cuestión de lotería. Y cuanto menor sea el desarrollo dogmático, más lotería, hasta llegar a la más caótica y anárquica aplicación de un Derecho penal del que -por no haber sido objeto de un estudio sistemático y científico- se desconoce su alcance y su límite".

19. Por ejemplo, Welzel 1997: 1. También, Roxin 1997: $§ 7$ nm. 1 y Silva Sánchez 1992: 47-50.

20. Así, Gimbernat Ordeig (1990: 158) menciona que leyéndose los manuales alemanes uno puede saber que rige en el código civil o penal, lo que no ocurre en otras latitudes donde no hay dogmática. Llama la atención que no haya ejemplificado esto último de alguna manera.

21. Roxin 2000: 49 ff. y Bacigalupo 1995: 62. 
22. Bacigalupo 1995: 62.

23. Silva Sánchez 1992: 70 ff. See also, Roxin 2000: 58-61, al especificar la función de protección de garantías constitucionales y Gimbernat Ordeig: 1999: 83.

24. Es usual añadir que esa distinción tardó mucho más en desarrollarse en aquellos lugares que carecen de dogmática penal. Al respecto, véase Schünemann 2008: 5 ff. Y Fletcher 1985: 949-982.

25. Pero debe quedar claro que no se trata de evaluar la coherencia de 'la' dogmática, entendida como conjunto de doctrinas que discuten sobre los fundamentos, la estructura o las consecuencias de la dogmática. Esto es así, básicamente, porque cada sistema tiene sus propias premisas y sus propias consecuencias. De hecho, la discusión sobre cuál es el sistema 'correcto' es una de las cuestiones más discutidas desde von Liszt hasta la actualidad. Al respecto, véase, Naucke 2002: $\$ 7$ nm. 3, y Pawlik 2012.

26. Para un resumen de algunas de estas críticas, véase, Salas 2006: 259-276.

27. Existe una vasta bibliografía que explora las relaciones entre legalidad, Estado de Derecho y determinación de la ley penal. Véase, por ejemplo, Madrid 1983.

28. En ocasiones, las reinterpretaciones dogmáticas son especificaciones que reducen el alcance de una norma penal. Es usual entender, en esos casos, que eso no es una infracción a la exigencia del principio de legalidad ya que supondría únicamente una elaboración analógica favorable a los imputados. Véase, Montiel 2009.

29. Endicott 2000: 187.

30. Acerca de las diferentes nociones de Estado de Derecho, véase: Raz 1979: 210-229.

31. Hay diferentes propuestas para explicar la fuerza institucional de las normas jurídica, pero todas ellas tienen que dar cuenta de un hecho básico: que el derecho no es un sistema de libre discreción y que los jueces tienen que justificar sus decisiones en normas que regulan los casos en cuestión. Acerca del alcance y la fuerza de las normas, véase, Navarro 2005: $29 \mathrm{ff}$.

32. Schauer 1991: $53 \mathrm{ff}$.

33. Acerca de la irrazonabilidad de estos límites, véase, Gimbernat Ordeig 1990: 260

34. Hart 1994: 130-134.

\section{RESÚMENES}

El trabajo pretende mostrar que la expansión de la dogmática, sobre todo en el discurso penal, representa un desafío al legislador y cuál es el precio que debemos pagar por ello. La dogmática, al igual que la legislación, necesita ofrecer al juez pautas precisas que sirvan para delimitar las decisiones correctas y, en ese mismo sentido, identificar a las que se consideran arbitrarias. Sólo bajo este supuesto la dogmática contribuye a lograr decisiones más previsibles. La dificultad radica en que la búsqueda de precisión puede limitar la arbitrariedad de los órganos de aplicación, pero, a la vez, la precisión introduce distinciones arbitrarias. En ciertos casos la arbitrariedad se produce por la indeterminación que generan las normas imprecisas y en otros casos, la arbitrariedad consiste en que al aplicar normas precisas, los funcionarios se apartan de las razones que justifican a esas normas. El desafío para la dogmática es mostrar que su contribución a la racionalidad puede superar a las que elabora el legislador. Es decir, debe mostrar por qué sus normas pueden tener éxito donde el legislador, por cuestiones conceptuales, inevitablemente fracasa. Los autores de este trabajo sostienen que la incorporación de normas dogmáticas en el horizonte de justificación de las decisiones no solo posee las mismas dificultades 
conceptuales que las del legislador sino que sus soluciones compiten con otras justificaciones formales, e.g. normas legisladas y, con frecuencia, suponen una tensión entre las palabras de la ley y lo que los dogmáticos dicen que dice el legislador.

ÍNDICE

Palabras claves: dogmática, autoridad, principio de legalidad, obediencia al legislador

\section{AUTORES}

\section{MARÍA LAURA MANRIQUE}

CONICET - Universidad Nacional de Córdoba (Argentina)

Address: Centro de Investigaciones Jurídicas y Sociales - Caseros 301 - 5000 Córdoba Argentina.

E-mail: laumanrique@hotmail.com

\section{PABLO E. NAVARRO}

CONICET - Universidad Blas Pascal (Argentina)

Address: Centro de Investigaciones Jurídicas y Sociales - Caseros 301 - 5000 Córdoba Argentina.

E-mail: pabnav@hotmail.com

JOSÉ M. PERALTA

CONICET - Universidad Nacional de Córdoba (Argentina)

Address: Centro de Investigaciones Jurídicas y Sociales - Caseros 301 - 5000 Córdoba Argentina.

E-mail: miltonjose75@hotmail.com 